\title{
KUM ZEMINE OTURAN KARE TEMEL ALTINDA OLUŞAN YANAL GERILMELERİN DENEYSEL VE TEORİK İNCELEMESİ
}

\author{
Hüseyin Suha AKSOY ${ }^{1}$ (ORCID: 0000-0003-0564-457X)* \\ Damla KÜÇÜKAY² (ORCID: 0000-0003-2021-1318) \\ Mesut GÖR ${ }^{1}$ (ORCID: 0000-0002-5463-9278)
}

\author{
${ }^{1}$ Inşaat Mühendisliği Bölümü, Mühendislik Fakültesi, Fırat Üniversitesi, Elazığ, Türkiye \\ ${ }^{2}$ Inş̧aat Mühendisliği Bölümü, Mühendislik Fakültesi, Yüzüncü Yll Üniversitesi, Van, Türkiye
}

Geliş/Received: 16.08 .2018 Kabul / Accepted: 13.02.2019

\begin{abstract}
ÖZ
Bu çalışmada, farklı rölatif sıkılıklarda hazırlanmış kum zemine oturan kare kesitli bir temel modellenmiştir. Model temelin düşey yüklenmesi sonucu oluşan yanal gerilmeler deney tankının cidarına yerleştirilen basınçölçerler (transduser) yardımıyla belirlenmiş̧ir. Deneyler $75 \times 75 \times 100 \mathrm{~cm}$ boyutlarındaki kare kesitli bir kum tankı içerisinde gerçekleştirilmiştir. $\% 10, \% 40, \% 65$ ve $\% 90$ rölatif sıkılıkta hazırlanan kum zemin üzerine yerleştirilen $15 \times 15 \mathrm{~cm}$ boyutlarındaki kare temel ile yüklemeler yapılmıştır. Yapılan deneyler sonucunda, tank cidarındaki basınç gerilmeleri başlangıçta temele yakın olan ilk $20 \mathrm{~cm}$ 'de artış göstermiş, sonraki derinliklerde giderek azalmış ve $50 \mathrm{~cm}$ derinlikte minimum değere ulaştığı görülmüştür. Deneysel olarak ölçülen zemin kütlesi içerisinde oluşan yanal gerilmeler, Boussinesq teorisinden hareketle elde edilen sonuçlarla karşılaş̧ırılmıştır.

Çalışmanın ikinci kısmında ise geometrik parametreler ve rölatif sıkılık gibi değişkenler yardımıyla zemin kütlesinde oluşacak gerilmelerin tahmini için kullanılabilecek bir bağıntı önerilmiștir. Yapılan regresyon analizi neticesinde, model deneyin yapıldığı ortama bağlı olan geometrik parametreler ile yanal gerilmeler arasındaki ilişki belirlenmiştir.
\end{abstract}

Anahtar kelimeler: Model deneyleri, kare temel, rölatif sıkılık, yanal gerilme, regresyon analizi

\section{EXPERIMENTAL AND THEORETICAL ANALYSIS OF LATERAL PRESSURES UNDER SQUARE FOUNDATION RESTING ON SAND}

\begin{abstract}
In this study, a square foundation sitting on sandy soils are modelled. The lateral stresses resulting from the vertical loadings of the model foundation were measured with pressure transducers placed on the wall of the test tank. Experiments are carried out in a square sand tank with dimensions of $75 \times 75 \times 100 \mathrm{~cm}$ in the laboratory. Sand which have $10 \%, 40 \%, 65 \%$ and $90 \%$ relative densities were prepared and a square foundation of $15 \times 15 \mathrm{~cm}$ placed on it. The stresses which occurred on sand tank walls initially increased in the first $20 \mathrm{~cm}$, which was close to the base of the foundation, gradually decreased in the subsequent depths and reached the minimum value in $50 \mathrm{~cm}$.

In the second part of the study, a correlation is proposed which can be used for estimation of stresses in the ground mass with the help of variables such as geometric parameters and relative densities. As a result of the regression analysis, the relationship between the lateral stresses and the geometric parameters depending on the environment of the model experiment was established.
\end{abstract}

Keywords: Model experiments, square foundation, relative density, lateral stress, regression analysis

*Corresponding author / Sorumlu yazar. Tel.: +90 424237 0000; e-mail / e-mail: saksoy @ firat.edu.tr 


\section{GIRIŞ}

Yapı yükleri ve temellerin kendi ağırlıkları, temeller vasıtasıyla taşıyıcı zemin tabakasına aktarılır. Aktarılan yüklerden dolayı zemin kütlesi içerisinde gerilme artışları oluşur. Yapı yüklerinin zemin içerisinde oluşturduğu bu gerilmeler, sabit olmayıp derinlik boyunca değişim göstermektedir. Zemin ortamında düşey yüklerle birlikte diğer doğrultularda da gerilmeler oluşur. Yapıların zeminde oluşturduğu düşey gerilme artışıyla birlikte zeminde meydana gelen yanal gerilme değerlerinin de bilinmesi büyük önem taşımaktadır.

Yanal toprak basınçları birçok temel mühendisliği problemlerinde önemli bir tasarım parametresidir. İstinat duvarları ve palplanş perdelerde, kazı kaplamalarında, danelerin saklandığı depo ve silolarda, toprak veya kaya ile temas eden tünel duvarlarında ve diğer yeraltı yapılarının tasarım ve stabilite analizinde yanal basınç değerleri kulanılarak tasarımlar yapılmaktadır [1]. Şekil 1.' de zemin yüzeylerine etkiyen yükler ve zemin kütlesindeki basınç dağılımları görülmektedir [2].

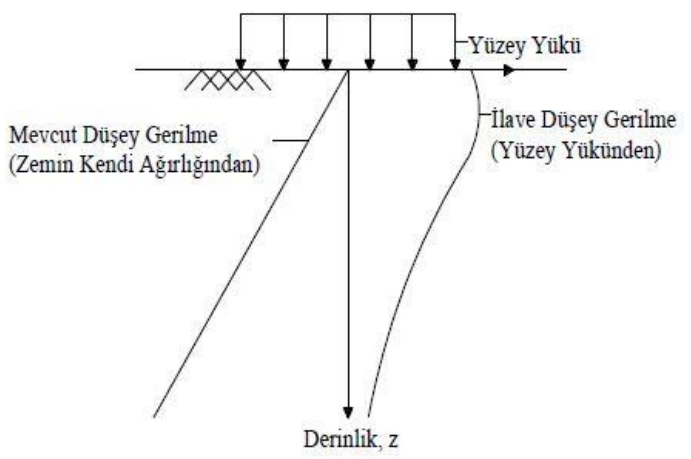

Şekil 1. Zeminde mevcut düşey gerilme ve düşey gerilme artışı dağılımları [2]

Zeminlerde oluşan bu gerilmeler, geoteknik mühendisliğindeki birçok problemin çözüm aşamasında ve projelerin tasarımında oldukça önemlidir. İnşa edilecek yapının güvenliği için taşıyıcı görevi üstlenen zemin tabakasında göçmeler ve aşırı oturmaların meydana gelmemesi gerekmektedir.

Zeminin karmaşık yapısından dolayı zemin içerisinde gerçek bir şekilde gerilme-deformasyon ölçümü yapmak oldukça zordur [2]. Gerilme artışları bazı kabuller yaparak çözümlenmeye çalışılmıştır. Bu sebeple genellikle yaklaşık bir çözüm sunan elastisite teorisinden faydalanılır [3]. Bu teori kullanılırken zemin elastik, homojen, izotrop ve yarı sonsuz olarak kabul edilmektedir. Bu kabuller yaklaşık olmakla birlikte mühendislik analizlerinde makul sonuçlar vermektedir.

Elastisite teorisi ile yapılan hesaplamalarda, zemin cinsi ve sıkılık gibi parametreler dikkate alınmaz ve her cins zemin için aynı gerilme dağılımları elde edilir [4]. Bununla birlikte yapılan deneysel çalışmalarda, granüler zeminde düşey gerilme değerlerinin, sıkılığa bağlı olarak önemli ölçüde farklılıklar gösterdiği gözlemlenmiştir [5]. Gerilme değerlerinin daha gerçekçi şekilde belirlenebilmesi için laboratuvar ortamında model deney teknikleri geliştirilmiştir. Bu deneysel çalışmalardan önce elastisite teorisinden faydalanarak çok sayıda teorik çalışma yapılmıştır. Elastisite teorisinden yararlanılarak elde edilen bu çözümlerden en çok kullanılanı Boussinesq [3] tarafından elde edilen çözümdür. Bu çözüme göre, temel üzerine etkiyen gerilme tesiri için, Boussinesq formülünde düşey gerilme Eşitlik 1.1'de verilmiştir. Bu eşitlikte, $\Delta \sigma_{z}$; düşey gerilme artışı $\left(\mathrm{kN} / \mathrm{m}^{2}\right)$ $\mathrm{q}_{0}$; birim yük miktarı $\left(\mathrm{kN} / \mathrm{m}^{2}\right)$, I ise etki faktörünü göstermektedir.

$\Delta \sigma_{z}=q_{0} . \mathrm{I}$

İstenilen derinlikteki düşey basıncı elde etmek için, Şekil 2'de verilmiş olan m ve n değerleri hesaplanır ve yine aynı şekildeki abaktan I (etki değeri) değeri okunur. Son olarak Eşitlik 1.1 kullanılarak üniform şekilde yüklenmiş dikdörtgen alanın köşesi altındaki düşey gerilme elde edilir [6].

Morgan ve Gerard'a göre granüler zeminlerde model temeller kullanılarak düşey gerilme ölçümü yapılmış çalışmalar özetlenmiş ve sonuçların elastisite teorisi kullanılarak elde edilen çözümlerle uyum içinde olduğunu belirlenmiştir [7]. Burland vd. non-lineerlik, non-homojenlik ve anizotropi etkilerini birçok zemin durumunu göz önüne alarak incelemiş ve Boussinesq denklemlerinin, yüklü alanlar altındaki gerilme dağılımını kabul edilebilir doğrulukta verdiğini belirtmiştir [8].

Yapılan bu çalışma kapsamında, farklı rölatif sıkılıklarda hazırlanmış zeminlere oturan kare kesitli model temelin yüklenmesi neticesinde zemin kütlesinde oluşan yanal gerilmeler ölçülmüştür. Deneysel sonuçlar Boussinesq yöntemiyle hesaplanan gerilmeler ile kıyaslanmıştır. Çalışmanın ikinci kısmında ise deney 

TEORIK INCELEMESI

sonuçlarından, açı ve mesafe gibi geometrik değişkenler ve zeminin rölatif sıkılık değerleri yardımıyla zemin kütlesinde oluşacak gerilmelerin tahmini için kullanılabilecek bir bağıntı önerilmiştir.

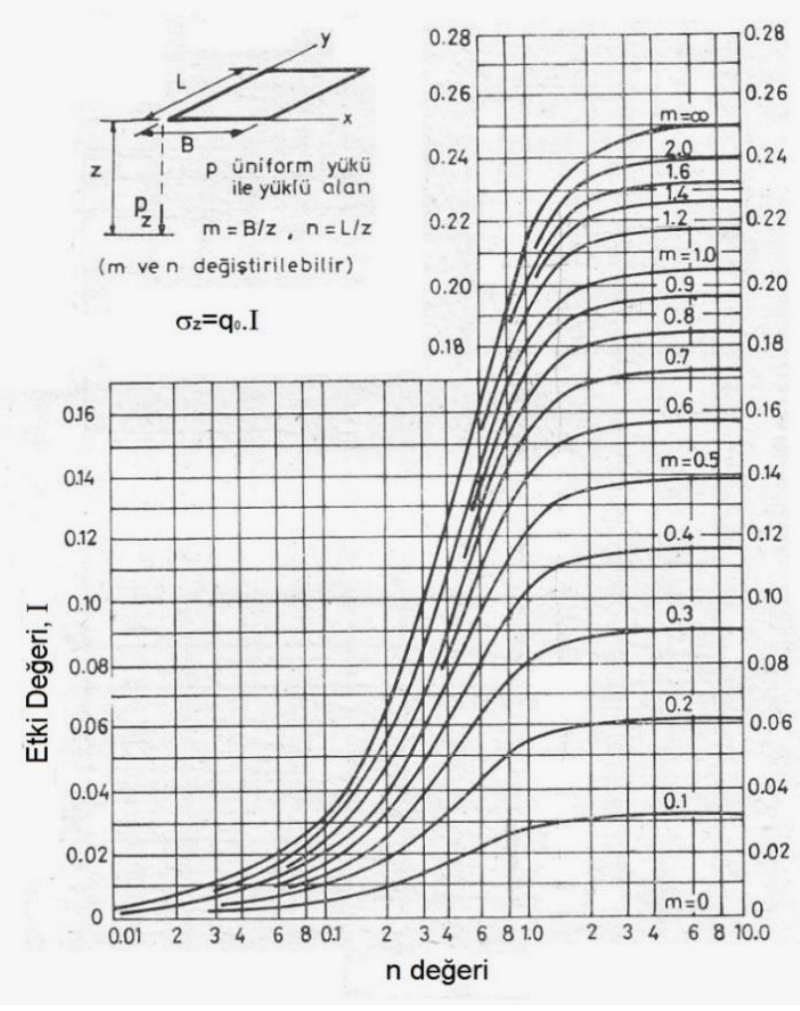

Şekil 2. Üniform yüklenmiş dikdörtgen alanın köşesi altındaki düşey gerilme için etki değeri [6]

\section{MATERYAL VE METOT}

Laboratuvarda yapılan model deneylerinde kullanılmak üzere dere kumu temin edilmiş ve yıkanıp elenerek uygun granülometride hazırlanmıştır. Hazırlanan kumun toplam hacmi $2 \mathrm{~m}^{3}$ tür. Deneyler, İnşaat Mühendisliği Bölümü Geoteknik Laboratuvarı'nda bulunan 75x75x100cm boyutlarındaki kare kesitli bir kum tankı içerisinde gerçekleştirilmiştir. Deney kasasının iskeleti çelik profillerden olup ön ve arka yüzeyi $8 \mathrm{~mm}$ kalınlığındaki cam, malzemeden yapılmıştır. \%10, \%40, \%65 ve \%90 rölatif sıkılıklarda hazırlanan kum zemin üzerine yerleştirilen $15 \times 15 \mathrm{~cm}$ boyutlarındaki kare temel üzerine yüklemeler yapılmıştır. Zemin kütlesi içerisindeki gerilme değişimleri mini basınçölçerler (pressure transducer) yardımıyla ölçülmüştür. Deney sonuçları Testbox 1001 marka dijital datalogger kullanılarak bilgisayar ortamında kaydedilmiştir.

\subsection{Deneylerde Kullanılan Zemin Özellikleri}

Laboratuvar deneylerinde, Elazığ ilinden temin edilen dere kumu kullanılmıştır. Dere kumu malzemesinin rengi siyah tonda olup bazalt kökenlidir. Bu zemin, birleştirilmiş zemin sınıflandırma sistemine (USCS) göre SP (kötü derecelendirilmiş kum) sınıfındadır. Deneylerde kullanılan kumun granülometri eğrisi Şekil 3'te görülmektedir.

Deneylerde kullanılan zemin üzerinde, ASTM C127-15, ASTM D854-14 ve ASTM D422- 63(2007)e2 standartlarına uygun şekilde yapılan deneyler sonucunda bu zeminin endeks özellikleri elde edilmiştir ve Tablo 1.'de gösterilmiştir [9-10-11]. Yukarıda verilen rölatif sıkılıkta hazırlanmış kum numuneler üzerinde ASTM D3080 / D3080M-11 standardına uygun olarak kesme kutusu deneyleri yapılmıştır [12]. Kesme kutusu deneyleri sonucunda her bir sıkılıktaki numuneler için içsel sürtünme açısı $(\phi)$ değerleri belirlenmiştir. Bulunan içsel sürtünme açısı değerleri yardımıyla sükunetteki toprak basıncı katsayısı $\left(\mathrm{K}_{0}=1-\sin \phi\right)$ değerleri hesaplanmıştır. İçsel sürtünme açısı ve $\mathrm{K}_{0}$ değerleri Tablo 2.'de verilmiştir. 


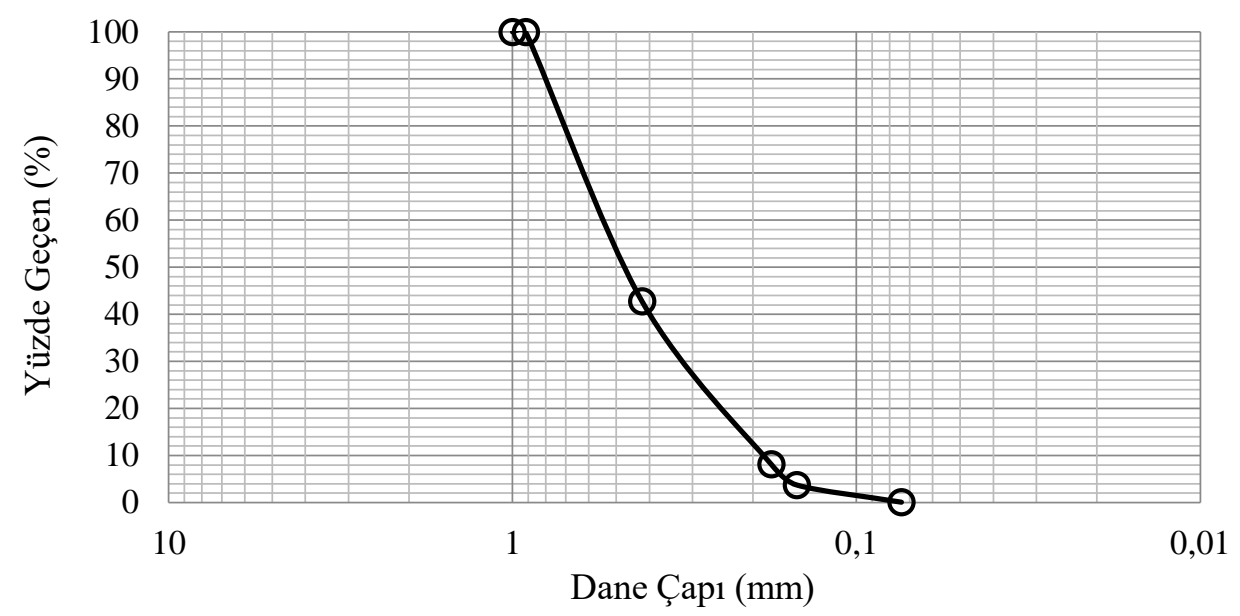

Şekil 3. Deneylerde kullanılan kum zeminin granülometri eğrisi

Tablo 1. Deneylerde kullanılan zeminin endeks özellikleri

\begin{tabular}{|l|c|}
\hline Dane birim hacim ağırlığı, $\mathrm{G}_{\mathrm{s}}$ & 2,77 \\
\hline $\mathrm{D}_{10}(\mathrm{~mm})$ & 0,18 \\
\hline $\mathrm{D}_{50}(\mathrm{~mm})$ & 0,45 \\
\hline Maksimum - Minimum Dane Boyutu, $\mathrm{D}_{\text {maks }}-\mathrm{D}_{\min }(\mathrm{mm})$ & $1-0,074$ \\
\hline Maksimum Kuru Birim Hac. Ağ. $\left(\mathrm{kN} / \mathrm{m}^{3}\right)$ & 17,5 \\
\hline Minimum Kuru Birim Hac. Ağ. $\left(\mathrm{kN} / \mathrm{m}^{3}\right)$ & 14,3 \\
\hline Maksimum Boşluk Oranı, $\mathrm{e}_{\mathrm{maks}}$ & 0,903 \\
\hline Minimum Boşluk Oranı, $\mathrm{e}_{\mathrm{min}}$ & 0,553 \\
\hline
\end{tabular}

Tablo 2. Farklı sıkılıklardaki kum zeminlerin içsel sürtünme açıları ve $\mathrm{K}_{0}$ değerleri

\begin{tabular}{|c|c|c|}
\hline Rölatif Sıkılık (Dr) & İçel Sürtünme Açısı $(\boldsymbol{\phi})$ & $\begin{array}{c}\text { Sükunetteki Toprak Basıncı } \\
\text { Katsayısı }\end{array}$ \\
\hline$\% 10$ & 42,8 & 0,32 \\
\hline$\% 40$ & 45,4 & 0,29 \\
\hline$\% 65$ & 49,4 & 0,24 \\
\hline$\% 90$ & 51,7 & 0,22 \\
\hline
\end{tabular}

\subsection{Deney Sisteminin Özellikleri}

Model deneylerinde, $15 \times 15 \mathrm{~cm}$ boyutlarındaki radye plak, planda $75 \times 75 \mathrm{~cm}$ boyutlarında olan ve derinliği $100 \mathrm{~cm}$ olan kum tank1 90cm'ye kadar farklı sıkılıkta doldurulup yüklenerek gerilme deformasyon ilişkisi belirlenmiştir (Şekil 4.) Ayrıca kum tankının cidarında farklı derinliklere yerleştirilmiş 6mm çaplı basınçölçerler vasitasıyla yanal gerilme değerleri ölçülmüştür.

Kum zemini deney tankı içerisine tabakalar halinde dört farklı sıkılıkta yerleştirilmiştir. Bu amaçla her $10 \mathrm{~cm}$ de bir kum tabakası, elektrikle çalışan 12 joule 'lük el kompaktörü ile sıkıştırılmıştır. Farklı zemin sıkılıkları elde etmek için yağmurlama ve el kompaktörü kullanılmıştır. $\mathrm{D}_{\mathrm{r}}=\% 10$ için sadece yağmurlama, $\mathrm{D}_{\mathrm{r}}=\% 40, \mathrm{D}_{\mathrm{r}}=\% 65$ ve $\mathrm{D}_{\mathrm{r}}=\% 90$ için yağmurlamaya ilaveten zemin yüzeyine sırası ile 1,3 ve 15 saniye el kompaktörü uygulanmıştır. Kum zemin, $10 \mathrm{~cm}$ 'lik tabakalar halinde sıkılık derecesi, $\mathrm{D}_{\mathrm{r}}=\% 10$ ve kuru birim hacim ağırlığ $\gamma_{k}=14,9 \mathrm{kN} / \mathrm{m}^{3}$, $\mathrm{D}_{\mathrm{r}}=\% 40$ ve kuru birim hacim ağırlı̆g $\gamma_{k}=15,7 \mathrm{kN} / \mathrm{m}^{3}, \mathrm{D}_{\mathrm{r}}=\% 65$ ve kuru birim hacim ağırlı̆̆ $1 \gamma_{k}=16,5 \mathrm{kN} / \mathrm{m}^{3}$, $\mathrm{D}_{\mathrm{r}}=\% 90$ ve kuru birim hacim ağırlığ $\gamma_{k}=17,4 \mathrm{kN} / \mathrm{m}^{3}$ olacak şekilde yerleştirildikten sonra temel bu yüzeyler üzerine yerleştirilip yük- deformasyon ilişkisi belirlenmiştir. Basınçölçerler (transduser) tank cidarına Şekil 4'te 
gösterilen yerlere yerleştirilmiştir. Deneylerde ortalama $2.0 \mathrm{~mm} / \mathrm{dk}$ deformasyon hızı oluşacak şekilde yükleme yapılmıştır. Deneyler sırasında, deformasyonlar, eksenel düşey yük değerleri ve basınçölçerlerden alınan basınç ölçümleri saniyede iki veri olacak şekilde datalogger kullanılarak bilgisayara kaydedilmiştir. Model temel ve basınçölçerler Şekil 5 'te görülmektedir.

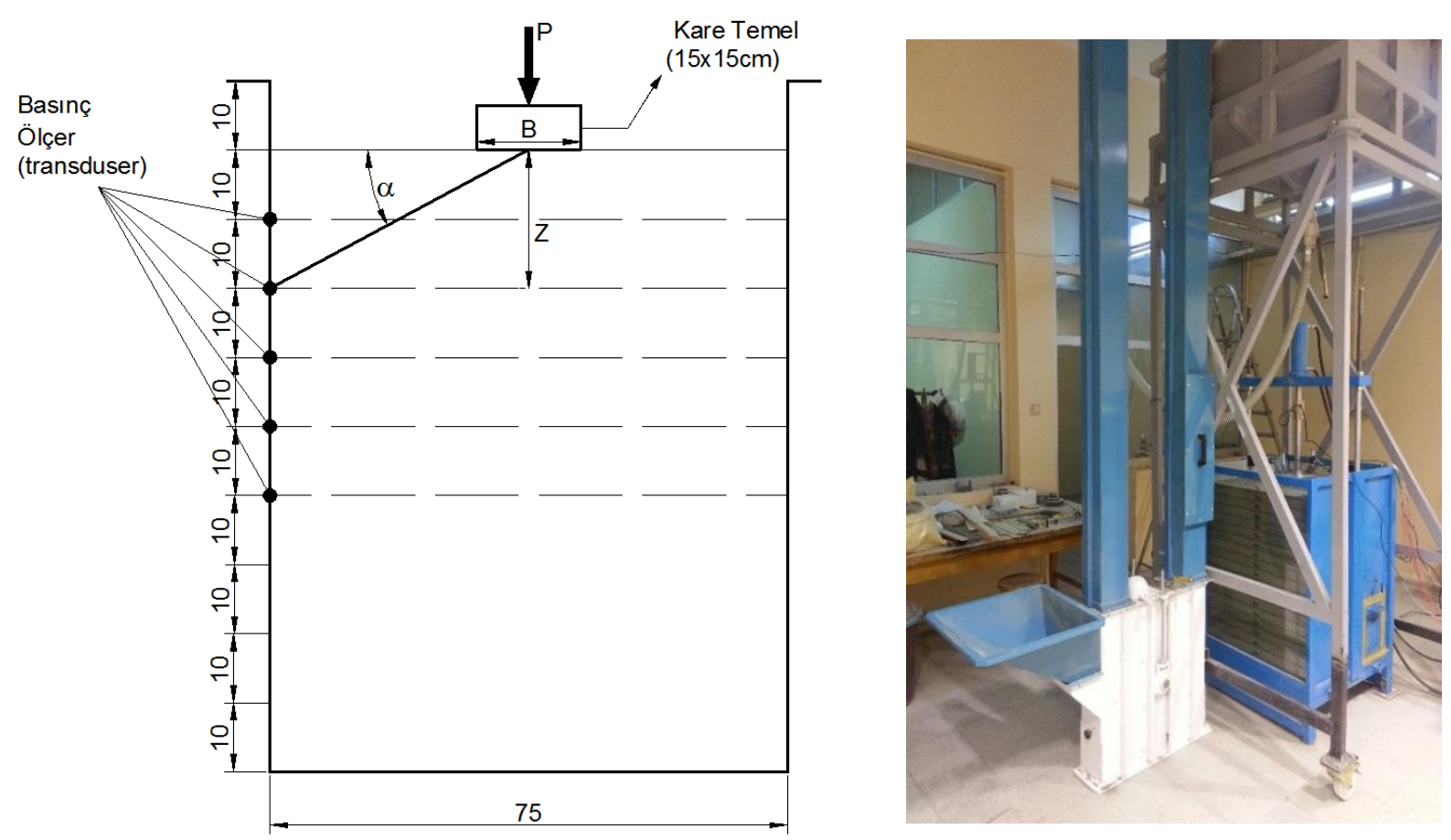

Şekil 4. Deney sistemi.

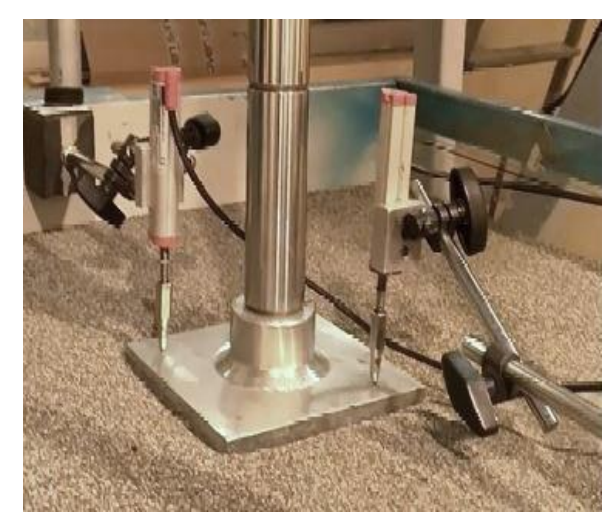

(a)

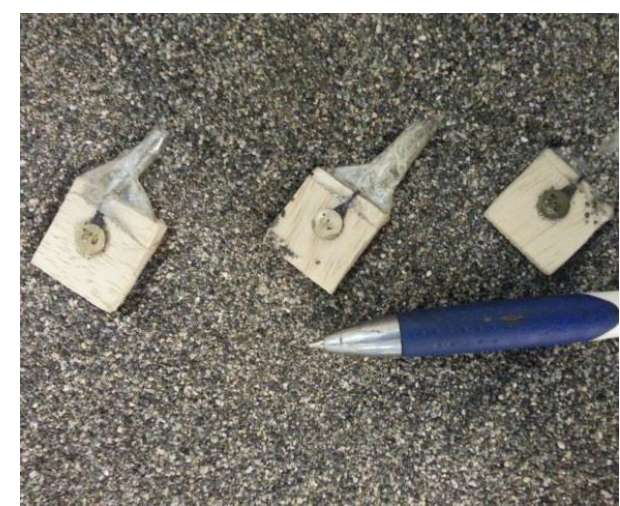

(b)

Şekil 5. (a) Model deneyde kullanılan kare temel, (b) Basınç ölçer

\section{BULGULAR VE TARTIŞMA}

\subsection{Deneysel Çalışmalar}

Model deneyde, dört farklı sıkılıkta doldurulan zemin kütlesi üzerine yerleştirilen temel, hidrolik yükleme sistemi yardımıyla yüklenmiş ve bu yükleme sonucunda temele ait yük-oturma ve kum tankı cidarındaki yanal gerilme değerleri ölçülmüştür. Temelde göçmenin meydana geldiği andaki yükler ve sınır taşıma gücü Tablo 3.'te gösterilmiştir. Yapılan yüklemeler sonucunda ölçülen yanal gerilme artışları $(\Delta \sigma h)$ Şekil 6 'da verilmiştir. Tablo 4.'te ise deneysel yanal gerilme verileri Bousinessq teorisi yardımıla hesaplanan yanal gerilme değerlerine bölünmüş ve orantılar hesaplanarak verilmiştir. 
Tablo 3. Model temelin taşıma gücü değerleri

\begin{tabular}{|c|c|c|}
\hline Rölatif Sıkılık (Dr) & Maks. Yük (kN) & $\mathbf{q}_{\mathbf{s} \text { smr }}\left(\mathbf{k N} / \mathbf{m}^{\mathbf{2}}\right)$ \\
\hline$\% 10$ & 1,44 & 64,00 \\
\hline$\% 40$ & 7,43 & 330,22 \\
\hline$\% 65$ & 15,49 & 688,44 \\
\hline$\% 90$ & 26,60 & 1182,22 \\
\hline
\end{tabular}

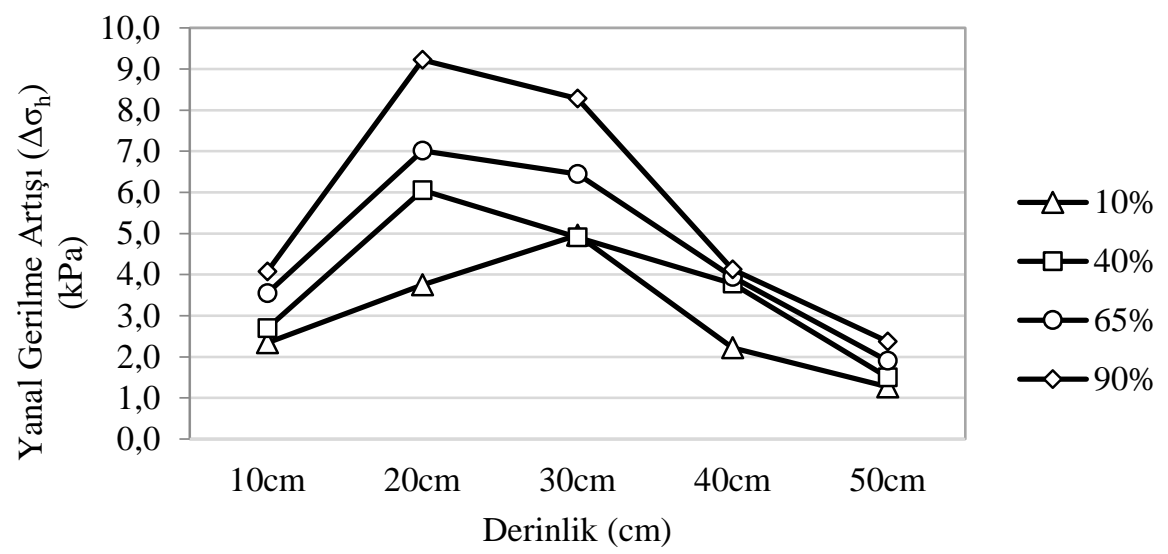

Şekil 6. Deneysel yanal gerilme- derinlik ilişkisi

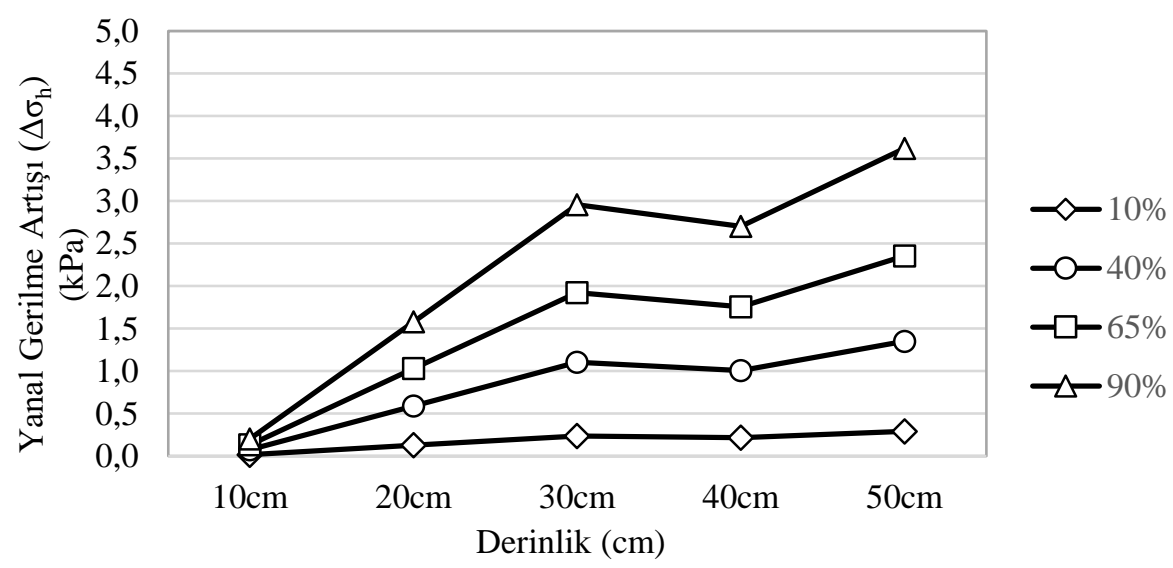

Şekil 7. Teorik (Boussinesq) yanal gerilme- derinlik ilişkisi

Tablo 4. Deneysel veriler ile teorik verilerin oranları

\begin{tabular}{|c|c|c|c|c|}
\cline { 2 - 5 } \multicolumn{1}{c|}{} & \multicolumn{4}{c|}{ Deneysel / Teorik $\mathbf{(} \boldsymbol{\Delta} \boldsymbol{\sigma}_{\mathrm{h} \text { deneysel }} / \mathbf{\Delta} \boldsymbol{\sigma}_{\mathrm{h}}$ teorik) } \\
\hline Derinlik & $\mathbf{\% 1 0}$ & $\mathbf{\% 4 0}$ & $\mathbf{\% 6 5}$ & $\mathbf{\% 9 0}$ \\
\hline $\mathbf{1 0} \mathbf{~ c m}$ & 142,7 & 35,4 & 26,8 & 20,0 \\
\hline $\mathbf{2 0 c m}$ & 29,5 & 10,3 & 6,8 & 5,8 \\
\hline $\mathbf{3 0} \mathbf{c m}$ & 20,9 & 4,4 & 3,4 & 2,8 \\
\hline $\mathbf{4 0 c m}$ & 10,2 & 3,8 & 2,2 & 1,5 \\
\hline $\mathbf{5 0 c m}$ & 4,4 & 1,1 & 0,8 & 0,7 \\
\hline
\end{tabular}


Üniform yüklenmiş dikdörtgen alanın köşesi altındaki düşey gerilme değerleri için model deney sistemi geometrisi kullanılarak Boussinesq yöntemine göre düşey gerilme hesabı yapılmıştır. Dört farklı sıkılık için kesme deneyleri ile hesaplanan içsel sürtünme açılarına bağlı $\mathrm{K}_{0}$ değerleri kullanılarak, deneylerden elde edilen düşey gerilmeler yardımıyla yanal gerilme artışları hesaplanmıştır.

\section{2. İstatistiksel Analiz}

Laboratuvar çalışmalarından elde edilen; yanal gerilme artışları $\left(\Delta \sigma_{\mathrm{h}}\right)$, rölatif sıkılık $\left(\mathrm{D}_{\mathrm{r}}\right)$, temel orta noktasıyla basınç trasduserini birleştiren doğrunun yatayla yaptığı açı $(\alpha)$ ve basınç trasduserinin yüzeyden itibaren derinliği (z) Tablo 5'de özetlenmiştir. Numunelere ait tanımsal istatistik parametreler Tablo 6'da verilmiştir.

Tablo 5. Model deneylere ait deneysel sonuçlar

\begin{tabular}{|c|c|c|c|c|c|}
\hline Deney No & $\boldsymbol{\Delta} \boldsymbol{\sigma}_{\mathbf{h}}(\mathbf{k P a})$ & $\boldsymbol{\alpha}\left(^{\circ}\right)$ & $\mathbf{z}(\mathbf{c m})$ & $\mathbf{z} / \mathbf{B}$ & $\mathbf{D}_{\mathbf{r}}(\boldsymbol{\%})$ \\
\hline PT-10-1 & 0,036563 & 14,93 & 10 & 0,67 & 10 \\
\hline PT-10-2 & 0,058594 & 28,07 & 20 & 1,33 & 10 \\
\hline PT-10-3 & 0,077500 & 38,66 & 30 & 2,00 & 10 \\
\hline PT-10-4 & 0,034688 & 46,85 & 40 & 2,67 & 10 \\
\hline PT-10-5 & 0,019844 & 53,13 & 50 & 3,33 & 10 \\
\hline PT-40-1 & 0,008146 & 14,93 & 10 & 0,67 & 40 \\
\hline PT-40-2 & 0,018321 & 28,07 & 20 & 1,33 & 40 \\
\hline PT-40-3 & 0,014839 & 38,66 & 30 & 2,00 & 40 \\
\hline PT-40-4 & 0,011447 & 46,85 & 40 & 2,67 & 40 \\
\hline PT-40-5 & 0,004542 & 53,13 & 50 & 3,33 & 40 \\
\hline PT-65-1 & 0,005157 & 14,93 & 10 & 0,67 & 65 \\
\hline PT-65-2 & 0,010182 & 28,07 & 20 & 1,33 & 65 \\
\hline PT-65-3 & 0,009369 & 38,66 & 30 & 2,00 & 65 \\
\hline PT-65-4 & 0,005723 & 46,85 & 40 & 2,67 & 65 \\
\hline PT-65-5 & 0,002760 & 53,13 & 50 & 3,33 & 65 \\
\hline PT-90-1 & 0,003443 & 14,93 & 10 & 0,67 & 90 \\
\hline PT-90-2 & 0,007799 & 28,07 & 20 & 1,33 & 90 \\
\hline PT-90-3 & 0,007004 & 38,66 & 30 & 2,00 & 90 \\
\hline PT-90-4 & 0,003485 & 46,85 & 40 & 2,67 & 90 \\
\hline PT-90-5 & 0,002005 & 53,13 & 50 & 3,33 & 90 \\
\hline
\end{tabular}

Tablo 6. Numunelerin tanımsal istatistik parametreleri

\begin{tabular}{|l|c|c|c|c|}
\hline & $\Delta \boldsymbol{\sigma}(\mathbf{k P a})$ & $\boldsymbol{\alpha}\left(^{\circ}\right)$ & $\mathbf{z} / \mathbf{B}$ & $\mathbf{D}_{\mathbf{r}}(\boldsymbol{\%})$ \\
\hline Ortalama & 0,01707 & 36,328 & 2 & 0,5125 \\
\hline Minimum & 0,002005 & 14,93 & 0,67 & 0,1 \\
\hline Maksimum & 0,0775 & 53,13 & 3,33 & 0,9 \\
\hline Stn. Sapma & 0,020151 & 13,95125 & 0,97 & 0,3043 \\
\hline Çarpıklık & 2,037849 & $-0,38246$ & $-1,5 \mathrm{E}-15$ & $-0,11236$ \\
\hline Basıklık & 3,821821 & $-1,20304$ & $-1,32$ & $-1,348$ \\
\hline
\end{tabular}


İstatistiksel analizde, rölatif sıkılık $\left(D_{r}\right)$, temel orta noktasıyla basınç trasduserini birleştiren doğrunun yatayla yaptığı açı $(\alpha)$ ve basınç trasduserinin yüzeyden itibaren derinliği (z) parametreleri kullanılarak tank cidarındaki yanal gerilme artışlarının $\left(\Delta \sigma_{h}\right)$ belirlenebilmesi için regresyon analizi yapılmıştır. Ancak bu şekilde yapılan analiz sonucunda basınç trasduserinin yüzeyden itibaren derinliği (z) parametresinin, tahmin sonuçlarını olumsuz yönde etkilediği görüldüğünden bu parametreninin temel genişliğine (B) bölünmesi ile elde edilen (z/B) parametresinin kullanılmasının daha uygun olacağı anlaşılmıştır.

Yapılan regresyon analizlerinde polinom fonksiyonlar denenmiş ancak elde edilen en iyi determinasyon katsayısı $\mathrm{R}^{2}=0,84$ olmuştur. Elde edilen determinasyon katsayısının düşük olması nedeniyle pek çok üstel fonksiyon denenmiş sonuçta determinasyon katsayısı $\mathrm{R}^{2}=0,99$ olarak elde edilmiştir. Yapılan istatistiksel analizlere ait sonuçlar Tablo 7.'de verilmiştir. Deneylerden elde edilen ve tahmin edilen verilerin karşılaştırılması Şekil 8'de görülmektedir. (2) eşitliğinde kullanılacak değişkenlere ait katsayılar Tablo 8.'de görülmektedir.

Tablo 7. Yapılan istatistiksel analizlerin toplu sonuçları

\begin{tabular}{|c|c|}
\hline & Model \\
\hline $\boldsymbol{\alpha}$ & 0,1949 \\
\hline $\mathbf{z} / \mathbf{B}$ & 1,2068 \\
\hline $\mathbf{D}_{\mathbf{r}}$ & $-6,4752$ \\
\hline Sabit & $-3,1168$ \\
\hline $\mathbf{R}^{\mathbf{2}}$ & 0,992 \\
\hline Tahminin Ortalama Hatası & 0,1242 \\
\hline
\end{tabular}

$\Delta \sigma=e^{\left(A \cdot \tan (\alpha)+B \cdot\left(\frac{z}{B}\right)+C \cdot\left(\frac{z}{B}\right)^{2}+E \cdot D_{r}+F \cdot D_{r}^{2}+G\right)}$

Tablo 8. Değişkenlere ait katsayılar

\begin{tabular}{|c|c|c|c|c|c|}
\hline $\mathbf{A}$ & $\mathbf{B}$ & $\mathbf{C}$ & $\mathbf{E}$ & $\mathbf{F}$ & $\mathbf{G}$ \\
\hline 0,195 & 1,207 & $-0,384$ & $-6,475$ & 3,704 & $-3,117$ \\
\hline
\end{tabular}

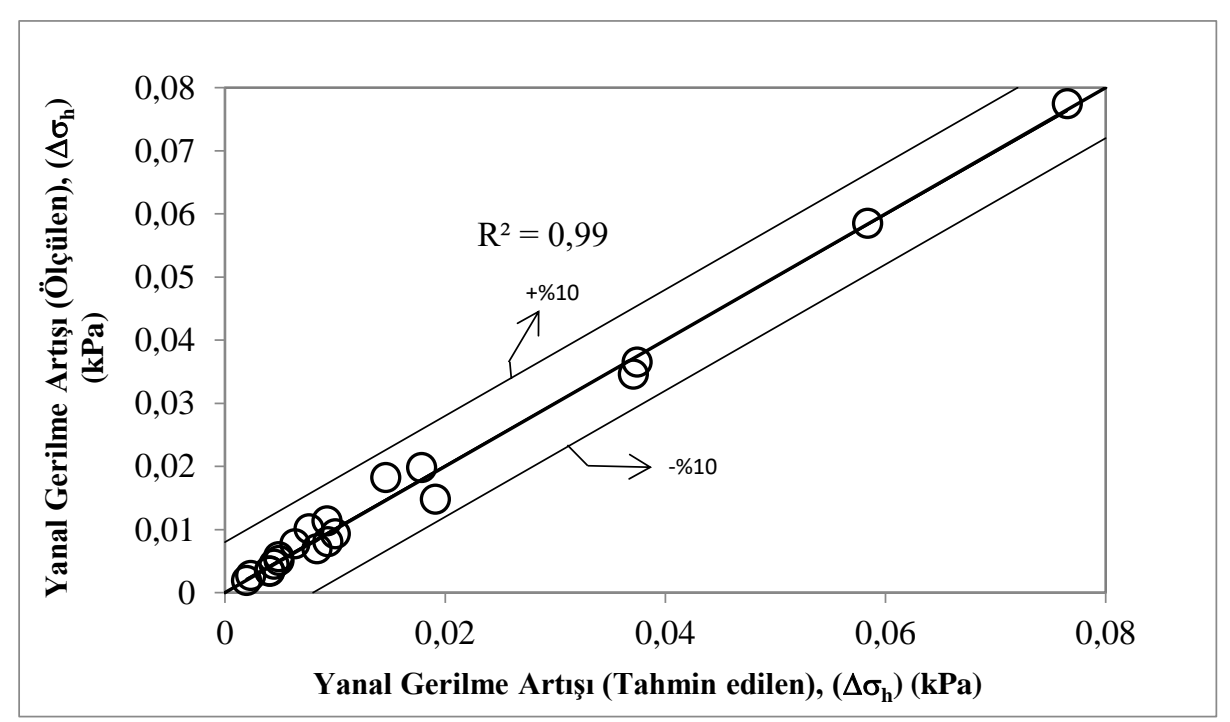

(a) 


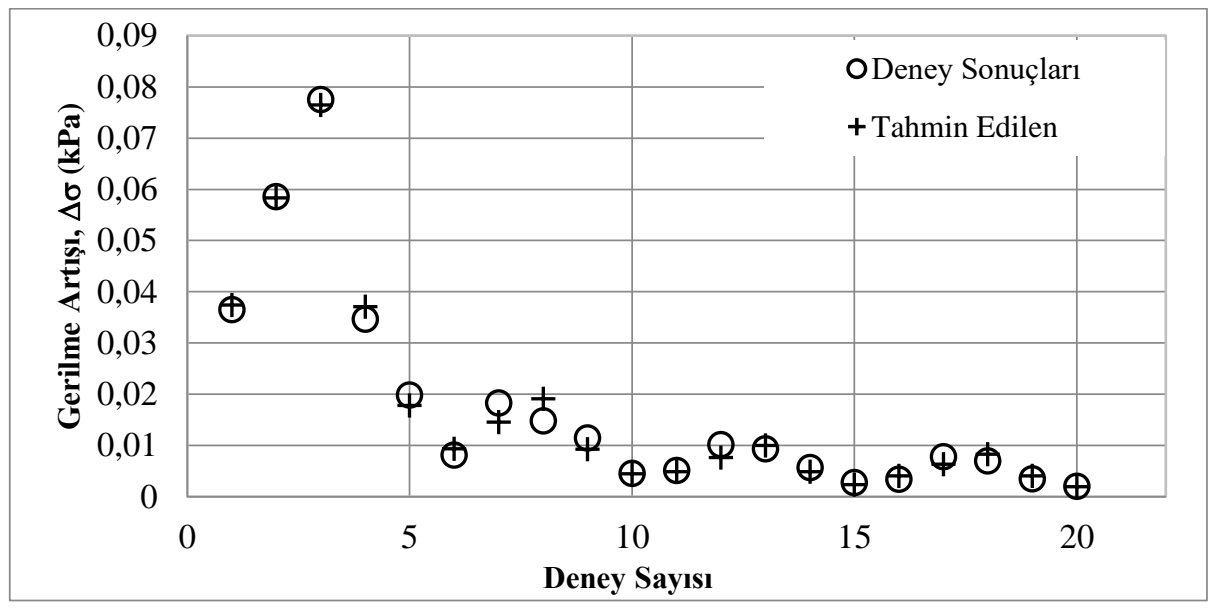

(b)

Şekil 8. (a), (b) Deney verilerinin tahmin edilen veriler ile karşılaştırılması

\section{SONUÇLAR}

Dört farklı rölatif sıkılıkta hazırlanmış zeminlere oturan kare kesitli bir temelin zemin kütlesi içerisinde oluşturduğu yanal gerilme artışları, laboratuvar ortamında model deneyleri ile belirlenmiş̧tir. Deneysel sonuçlar kullanılarak istatistiksel analizler yapılmış ve yanal gerilmelerin tahmini için bir bağıntı $\left(\mathrm{R}^{2}=0.99\right)$ önerilmiştir.

Model deneyler sonucunda, rölatif sıkılık arttıkça temelin taşıma gücünün $\left(\mathrm{Q}_{\text {snnrr }}\right)$ ve ölçülen yanal gerilme değerlerinin arttığı belirlenmiştir. Deneysel olarak ölçülen yanal gerilme değerleri, $\mathrm{D}_{\mathrm{r}}=\% 10$ dışında tüm sık1lıklarda $20 \mathrm{~cm}$ derinliğinde $(4 \mathrm{~B} / 3)$ maksimum değeri verdiği gözlemlenmiştir.

Boussinesq yöntemine göre hesaplanan yanal gerilme artı̧̧ değerlerinin ise $30 \mathrm{~cm}$ (2B) derinliğe kadar arttığı bu değerden sonra bir miktar azaldıktan sonra artmaya devam ettiği gözlemlenmiştir. Boussinesq yöntemine göre hesaplanan yanal gerilme değerlerinin $50 \mathrm{~cm}(10 \mathrm{~B} / 3)$ civarında maksimum olduğu ve bu derinlikten sonra azalmaya başladığı hesaplanmıştır. Ancak deneysel veriler yanal gerilmelerin artan derinlikle ( $\mathrm{z}>4 \mathrm{~B} / 3)$ beraber azaldığının ve $50 \mathrm{~cm}(10 \mathrm{~B} / 3)$ değerinden sonra ihmal edilebilecek seviyelere ulaştı̆̆ını göstermektedir. Teorik bağıntılarla hesaplanan yanal gerilme değerlerinin $40 \mathrm{~cm}(8 \mathrm{~B} / 3)$ derinliğe kadar gerçek değerlerden oldukça düşük olduğu ve bu derinlikten sonra gerçek değerlere yaklaşmaya başladığ 1 belirlenmiştir.

Model deneyin gerçekleştiği ortam geometrisi ve zeminin farklı rölatif sıkılık değeri dikkate alınarak yanal gerilme artış değerlerinin belirlenmesi için istatistiksel analiz yöntemlerinden yararlanılmıştır. Yapılan istatistiksel analizde, kare bir temel altındaki yanal gerilme değerlerini belirli bir yaklaşımla tahmin etmenin mümkün olacağı sonucuna varılmışıı. Bu amaçla bir eşitlik sunulmuştur. Analiz sonuçları göstermiştir ki, $\Delta \sigma$ değerinin yeterli bir yaklaşımla hesaplanabilmesi için rölatif sıkılık, zemine oturan temelin transduserlere olan mesafesinin ve temel orta noktasıyla basınç trasduserini birleştiren doğrunun yatayla yaptığı açı dikkate alınması yeterli olmaktadır.

Bu çalışma kapsamında, SP sınıfı bir zeminde laboratuvar ortamında yapılan model deneyleri neticesinde temellerin altında farklı derinliklerde oluşan yanal gerilmelerin gerçeğe yakın olarak tahmin edilebileceği anlaşılmıştır. Yanal gerilmelerin tahmin edilebilmesi, özellikle istinat yapıları gibi yanal gerilmelere göre projelendirilen mühendislik yapılarının boyutlarının doğru bir şekilde belirlenmesini ve proje maliyetlerinin düşmesini sağlayacaktır.

\section{KAYNAKLAR}

[1] BOWLES, J.E., Foundation Analysis and Design, Peoria, IL,1997.

[2] UZUNER, B.A., Çözümlü Problemlerle Temel Zemin Mekaniği, Teknik Yayınevi, Ankara, Türkiye, 2005.

[3] BOUSSINESQ, J., Application des Potentiels a L'etude de L'equilbre et du Movement des Solids Elastiques, Gauthier-Villars, Paris, France, 1885.

[4] SAĞLAMER, A., Kohezyonsuz Zeminlerde Sükunetteki Toprak Basıncı Katsayısının Zemin Parametreleri Cinsinden İfadesi, Doktora Tezi, İstanbul Teknik Üniversitesi, İstanbul,1972.

[5] LAMAN,M., KESKIN, M.S., "Kumlu Zeminlere Oturan Kare Temeller Altında Düşey Gerilme Analizi", 
Türkiye Mühendislik Haberleri, İMO, 431, 53-57, 2004.

[6] HOLTZ, R.D, KOVACS, W.D., SHEAHAN, C.T., An Introduction to Geotechnical Engineering, 2nd Edition, Pearson Co., Upper Saddle River, NJ, 2015.

[7] MORGAN, J.R., GERRARD, C.M., "Behavior of Sands Under Surface Loads", Journal of the Soil Mechanics and Foundation Division, ASCE, 97 (SM 12), 1675-1699,1971.

[8] BURLAND, J.B., BROMS, B.B., DE MELLO, V.F.B., "Behaviour of Foundations and Structures", In Proceedings of the 9th International Conference on Soil Mechanics and Foundation Engineering, 495-538, Tokyo, Japan, 1977.

[9] ASTM C127-15, Standard Test Method for Relative Density (Specific Gravity) and Absorption of Coarse Aggregate, ASTM International, West Conshohocken, PA, 2015.

[10] ASTM D422-63(2007)e2, Standard Test Method for Particle-Size Analysis of Soils, ASTM International, West Conshohocken, PA, 2007.

[11] ASTM D854-14, Standard Test Methods for Specific Gravity of Soil Solids by Water Pycnometer, ASTM International, West Conshohocken, PA, 2014.

[12] ASTM D3080 / D3080M-11 Standard Test Method for Direct Shear Test of Soils Under Consolidated Drained Conditions, ASTM International, West Conshohocken, PA, 2007. 